\title{
The Cytotoxic Effect of the Benzene Metabolite Hydroquinone is Mediated by the Modulation of MDR1 Expression via the NF-kB Signaling Pathway
}

\author{
Jianshu Huanga Mingdong Zhao ${ }^{b}$ Xiuju Lia Li Maa Jihong Zhang $^{\mathrm{c}} \quad$ Jimin Shic \\ Bing Lic Wei Fan ${ }^{c}$ Yuanling Zhou ${ }^{\mathrm{a}}$ \\ aDepartment of Occupational Disease, Jinshan Hospital, Fudan University, Shanghai, bDepartment of \\ orthopaedics, Jinshan Hospital, Fudan University, Shanghai, 'Department of Central Laboratory, Jinshan \\ Hospital, Fudan University, Shanghai, China
}

\author{
Key Words \\ Hydroquinone $\cdot$ MDR1 1 NF-KB
}

\begin{abstract}
:
Background/Aims: Benzene is a toxic chemical whose leukemogenic effects have been studied for decades. The mechanisms of benzene-induced toxicity and leukemogenicity are not fully understood, although the involvement of several pathways has been suggested, including oxidative stress, DNA damage, cell cycle regulation and programmed cell death. In the present study, we investigated the effect of hydroquinone $(\mathrm{HQ})$, a major benzene metabolite, on the viability of bone marrow derived mesenchymal stem cells (BMSCs) and explored the underlying mechanisms. Methods: First, we study the the effect of HQ on BMSCs cell viability, apoptosis and the expressions of MDR1 and NF-KB. Then we investigate the MDR1 on cell viability and cell apoptosis for BMSCs under HQ treatment. Finally, we studied the impact of nuclear factor $\mathrm{KB}(\mathrm{NF}-\mathrm{kB})$ on the expression of MDR1. Results: Our results showed that $\mathrm{HQ}$ decreased cell viability and promoted cell apoptosis of BMSCs, as determined by the MTT assay and flow cytometry. Western blotting and quantitative PCR showed that HQ downregulated the expression of the MDR1 gene by inhibiting the activation and nuclear translocation of the transcription factor NF-KB. Overexpression of MDR1 attenuated the inhibitory effect of HQ on cell viability in BMSC. Conclusion: The results of the present study suggest the involvement of the multidrug resistance membrane transporter MDR1 and the NF-kB pathway in the cytotoxicity of benzene and its metabolites. Further studies are necessary to clarify the role of the pathways involved and the crosstalk between them in mediating the effects of HQ in bone marrow progenitor cells.
\end{abstract}

Copyright $@ 2015$ S. Karger AG, Basel

J. Huang and M. Zhao contributed equally to this work.

Yuanling Zhou

KARGER 125
Department of Occupational Disease, Jinshan Hospital, Fudan University, Shanghai (China)

Tel. +86-21-34189990-5395, Fax+86-21-67226910, E-Mail zybktj@163.com 


\section{Cellular Physiology Cell Physiol Biochem 2015;37:592-602 \begin{tabular}{l|l} 
and Biochemistry Published online: September 8, 2015 & $\begin{array}{l}\text { DC 2015 S. Karger AG, Basel } \\
\text { www.karger.com/cpb }\end{array}$ \\
\hline
\end{tabular} \\ Huang et. al.: The Cytotoxic Effect of Hydroquinone is Mediated by MDR1}

\section{Introduction}

Benzene is a clear, colorless liquid that volatilizes in air and is commonly present in the atmosphere as a result of emissions from burning coal and oil, gasoline vapors, motor vehicle exhaust, cigarette smoke and wood-burning among other sources [1]. Human exposure to benzene occurs through inhalation, dermal absorption, the ingestion of contaminated food and drinking water, and active and passive tobacco smoking [2,3]. Benzene is converted into toxic metabolites including benzene oxide, phenol, hydroquinone (HQ), catechol, and 1,2,4-benzenetriol in the liver [4]. Benzene exposure has been shown to be correlated with the incidence of leukemia, in particular acute myeloid leukemia, but also acute and chronic lymphocytic leukemia, non- Hodgkin's lymphoma, multiple myeloma, and aplastic anemia $[5,6]$. Exposure to low levels of benzene has been associated with increased risk of myelodysplastic syndrome and decreased resistance to infection [7]. HQ, the most abundant pro-oxidant compound in cigarette smoke, can bind both DNA and protein and can induce oxidative stress. It can travel to the bone marrow, where it is oxidized to highly toxic quinones, thus contributing to the toxicity of benzene [8-10]. Despite extensive research into the effects of benzene and its metabolites, the mechanism underlying the toxicity of benzene remains to be fully elucidated.

The transcription factor nuclear factor $\kappa \mathrm{B}(\mathrm{NF}-\kappa \mathrm{B})$ inhibits apoptosis and induces resistance to chemotherapeutic drugs in cancer cells [11]. In unstimulated cells, NF- $\kappa B$ is retained in the cytoplasm by the inhibitor I $\mathrm{B}$, which is phosphorylated by the IKK kinase complex in response to different stimuli, promoting its ubiquitination and degradation, and freeing NF- $\kappa \mathrm{B}$ to translocate to the nucleus and induce the transcription of its target genes. The involvement of NF- $\kappa \mathrm{B}$ in drug resistance through the transactivation of the MDR1 gene has been proposed previously, and an NF- $\kappa B$ binding site was identified in the human MDR1 gene. Drug resistance can be mediated by decreased cellular drug uptake, which can be associated with overexpression of P-glycoprotein (P-gp), a membrane transporter that is encoded by the MDR1 gene. The transcriptional regulation of MDR1 has been studied extensively and a number of transcription factors have been implicated in the modulation of its expression including Ras, Sp1, p53, NF- $\mathrm{KB}$, and PKC [12-16]. In addition, extracellular stimuli such as heat shock and chemotherapeutic agents, as well as DNA methylation and histone acetylation have been involved in the regulation of MDR1 expression [17-20].

Mesenchymal stem cells (MSCs) are a multipotent population of non-hematopoietic cells that can differentiate into bone, cartilage, adipose and fibrous tissues in vitro or in vivo $[21,22]$. The development and optimization of techniques for the isolation, purification and expansion of bone marrow derived MSCs (BMSCs) stimulated extensive research into their characterization and differentiation potential. Furthermore, the finding that BMSCs secrete specific growth factors and cytokines that direct each differentiation pathway and that modulation of these molecules can induce a specific phenotypic lineage suggested the potential of these cells for tissue repair [23]. The multi-lineage potential of MSCs and their relative ease of handling in vitro have made them a powerful tool for tissue engineering [24, 25].

In the present study, we examined the effect of the benzene metabolite HQ on the expression of MDR1 in BMSCs and explored the mechanisms underlying benzene toxicity to identify novel targets for the treatment of chronic benzene poisoning.

\section{Materials and Methods}

\section{Isolation and culture of BMSCs [26]}

Newborn rabbits were sacrificed by sodium pentobarbital overdose under sterile conditions. The bilateral femurs were dissected with the proximal and distal ends snipped off, and bone marrow tissue was flushed out using a 1-mL sterile syringe with minimum essential medium (MEM; Gibco-BRL, Gaithersburg, MD, USA) containing 10\% fetal calf serum and antibiotics (100 U/mL penicillin and 100 $\mathrm{U} / \mathrm{mL}$ streptomycin). Following centrifugation at $800 \mathrm{rpm}$ for $5 \mathrm{~min}$, the cell pellets were collected and 
resuspended in fresh culture medium. Cells $(1 \times 105)$ were cultured in a $25-\mathrm{cm} 2$ culture flask at $37^{\circ} \mathrm{C}$ and $5 \%$ C02. The culture medium was changed every three days. Cells in the third passage were harvested for subsequent experiments.

\section{Cell viability assessment}

Cell viability was assessed using the MTT [3-(4,5-dimethylthiazol-2-yl)-2,5- diphenyltetrazolium bromide] assay. Cells at a density of $1 \times 10^{6} \mathrm{cells} / \mathrm{mL}$ were treated as indicated and then incubated with MTT ( $5 \mathrm{mg} / \mathrm{mL}$ in PBS) to a final concentration of $0.2-0.5 \mathrm{mg} / \mathrm{mL}$ for $4 \mathrm{~h}$. After removing the supernatant, the formazan precipitate was dissolved in DMSO and absorbance was read in an ELISA plate reader at $570 \mathrm{~nm}$. The results were expressed as a percent of the untreated control and all experiments were repeated three times.

Flow cytometric analysis of apoptosis with the Annexin V-FITC/PI assay

Cells were treated with HQ $(0,25,50,75,100$ and $125 \mu \mathrm{M})$ for $24 \mathrm{~h}$ prior to apoptosis assessment, which was performed as described previously (Siew et al., 2012). Briefly, $1 \times 10^{6}$ cells were collected and resuspended in $150 \mathrm{~mL}$ Annexin V buffer containing $2.5 \mathrm{ml}$ FITC-conjugated Annexin V and incubated for $15 \mathrm{~min}$ in the dark. Propidium iodide $(10 \mathrm{~mL}$ of $50 \mathrm{mg} / \mathrm{ml}$ stock in PBS) was then added and samples were subjected to flow cytometric analysis using FACS CANTO II (BD Bioscience).

$q t-P C R$

Total RNA was extracted using TRIzol Reagent (Invitrogen, Shanghai, People's Republic of China), according to the manufacturer's protocol. One microgram of total RNA was used to prepare cDNA by reverse transcription using a PrimeScript RT reagent kit (Takara, Dalian, People's Republic of China). The primer sequences were as follows (Table 1). cDNA was amplified using a SYBR Premix Ex Taq kit (Takara, Dalian, People's Republic of China) and an Mx3000p instrument (Agilent). The PCR protocol was as follows: one cycle of denaturation at $95^{\circ} \mathrm{C}$ for $30 \mathrm{~s} ; 40$ cycles of denaturation at $95^{\circ} \mathrm{C}$ for $5 \mathrm{~s}$; and annealing at $60^{\circ} \mathrm{C}$ for 20 s. PCR products were analyzed using the $\Delta \Delta \mathrm{CT}$ method with $\beta$-actin as the standard gene.

\section{Western blot analysis}

For preparation of nuclear extracts, cells were harvested, rinsed, and lysed in a hypotonic buffer consisting of $10 \mathrm{mM}$ HEPES (pH 7.4), $1.5 \mathrm{mM} \mathrm{MgCl2,10} \mathrm{mM} \mathrm{KCl}, 0.5 \mathrm{mM}$ dithiothreitol, phosphatase inhibitors (1 mM sodium orthovanadate and $10 \mathrm{mM}$ sodium fluoride), protease inhibitors ( $0.5 \mathrm{mM}$ phenylmethyl sulfonylfluoride, $1 \mu \mathrm{g} / \mathrm{mL}$ pepstatin A, $2 \mu \mathrm{g} / \mathrm{mL}$ leupeptin, and $2 \mu \mathrm{g} / \mathrm{mL}$ aprotinin), and 1\% Triton X-100.

For total cellular protein extracts, a total protein extraction kit (KeyGen Biotech, Nanjing, People's Republic of China) was used. For western blot analysis, lysates were separated on $15 \%$ polyacrylamide sodium dodecyl sulfate gels and electroblotted onto Immobilon-P membranes (Millipore Corp., Bedford, MA). After blocking in 5\% fat-free powdered milk in Tris-buffered saline with $0.05 \%$ Tween 20, membranes were incubated with primary antibodies against MDR1 (1:500; Abcam), $\beta$-actin (1:500; Santa Cruz Biotechnology,Inc), NF-kB p65 (1:1000; Santa Cruz Biotechnology, Inc.) for overnight at $4^{\circ} \mathrm{C}$. Secondary antibodies against horseradish peroxidase-conjugated anti-mouse IgG were purchased from Cell Signaling Technology (Beverly, MA, USA). Proteins were visualized with enhanced chemiluminescence.

\section{Immunofluorescence}

Cells were grown on coverslips and cultured for $24 \mathrm{~h}$. After treatment with the indicated doses of HQ, the cells were fixed in 4\% paraformaldehyde for $15 \mathrm{~min}$, washed in PBS, and treated for $15 \mathrm{~min}$ with PBS containing $0.1 \%$ Triton X-100. The cells were then washed, blocked with $10 \%$ bovine serum albumin (BSA) for $1 \mathrm{~h}$ at room temperature, and incubated at $4^{\circ} \mathrm{C}$ overnight with NF- $\mathrm{KB}$ p65 antibody (1:100) diluted in $0.1 \%$ BSA. After extensive washing, a 1:200 dilution of Dylight 649 conjugated goat anti-mouse immunoglobulin was applied as the
Table 1. The primer sequences used for quantitiative real-time PCR

\begin{tabular}{cc}
\hline Primer & Sequence $\left.\left(5^{\prime}-3^{\prime}\right)\right)$ \\
\hline MDR1-F & F:GTGAGGTATCTGCGGGAAATTA \\
MDR1-R & R: GTGACATCTTCTCGGCCATAG \\
GAPDH & F:GGCAAGTTCAACGGCACAG \\
GAPDH & R:CGCCAGTAGACTCCACGAC \\
\hline
\end{tabular}


secondary antibody for $1 \mathrm{~h}$ at room temperature. Nuclear staining was achieved by incubating cells in DAPI for $5 \mathrm{~min}$. The slides were then washed and photographed with an OLYMPUS 1X71 fluorescence microscope.

Transient transfections and luciferase assays

For DNA transfection, cells were plated at a density of $2.0 \times 10^{5}$ cells per well in six-well culture dishes. After $24 \mathrm{~h}$, the cells were transfected with a construct containing a luciferase reporter gene driven by a fragment of the MDR1 promoter region together with expression vectors for the NF-kB protein. The $\mathrm{p} 225$ plasmid contains a 976 bp PCR-generated fragment of the MDR1 gene that was subcloned into the pGL3Basic vector (Promega, Madison, WI, USA) upstream of the luciferase reporter gene. Cells were transfected using the Fugenet 6 transfection reagent as recommended by the manufacturer (Roche, Mannheim, Germany). A Renilla luciferase plasmid was also cotransfected in each experiment as an internal control for transfection efficiency. Approximately $24 \mathrm{~h}$ after the beginning of the transfection, cells were lysed and Luciferase assays were performed using the Dual Luciferase Reporter Assay System (Promega). Results were expressed as luciferase activity relative to the empty vector control.

\section{Statistical analysis}

Date were presented by as means \pm standard deviations(SD). Statistical analysis was performed by using the statistical package social science(SPSS) program, version 17.0. Student T-test was used to determine statistical significance. A p-value less than 0.05 was considered significant and p-value less than 0.01 was considered highly significant.

\section{Results}

$H Q$ affects the viability and apoptosis of BMSCs

BMSCs were incubated with increasing doses of HQ (Fig. 1A) or with a single dose of HQ $(125 \mu \mathrm{M})$ for different times from 2 to $10 \mathrm{~h}$ (Fig. 1B) and cell viability was assessed using the MTT assay. HQ caused a significant dose and time dependent inhibition of BMSC viability $(\mathrm{p}<0.05)$. Assessment of apoptosis in response to increasing concentrations of HQ from 25 $\mu \mathrm{M}$ to $125 \mu \mathrm{M}$ showed a dose dependent significant increase in the rate of BMSC apoptosis (Fig. 1C, D).

\section{$H Q$ downregulates the expression of MDR1 $m R N A$ and protein}

BMSCs were exposed to increasing concentrations of HQ from $25 \mu \mathrm{M}$ to $125 \mu \mathrm{M}$ and the expression of MDR1 was assessed by quantitative PCR (qPCR) (Fig. 2A) and western blotting (Fig. 2B). The results showed that HQ downregulated the expression of MDR1 in a dose-dependent manner at the mRNA and protein levels.

\section{Effect of MDR1 overexpression or silencing on the response of BMSCs to $H Q$}

BMSCs were transfected with vectors overexpressing or silencing MDR1, and cell viability and apoptosis were assessed in response to treatment with increasing concentrations of HQ. Ectopic expression of MDR1 attenuated the effect of HQ on the inhibition of cell viability (Fig. $3 \mathrm{~A}$ ) and the induction of apoptosis (Fig. 3B), and the effect was stronger in response to $\mathrm{HQ}$ at 75 and $100 \mu \mathrm{M}(\mathrm{p}<0.05)$. Knockdown of MDR1 expression, on the other hand, enhanced the effect of HQ on cell viability and apoptosis, but the effect was only detectable at certain concentrations.

\section{$H Q$ inhibits the nuclear translocation of $N F-\kappa B$}

To determine whether the effect of HQ on BMSC viability via the modulation of MDR1 expression was mediated by the NF- $\kappa B$ pathway, the expression of the nuclear NF- $\kappa B$ p-p65 was assessed in nuclear extracts of BMSCs treated with different concentrations of HQ. The results showed that the levels of the nuclear NF- $\kappa \mathrm{B}$ p-p65 decreased in response to HQ in a dose-dependent manner (Fig. 4A and B). Furthermore, immunofluorescence detection of NF- $\kappa$ B p65 in BMSCs treated with different concentrations of HQ showed a dose-dependent 


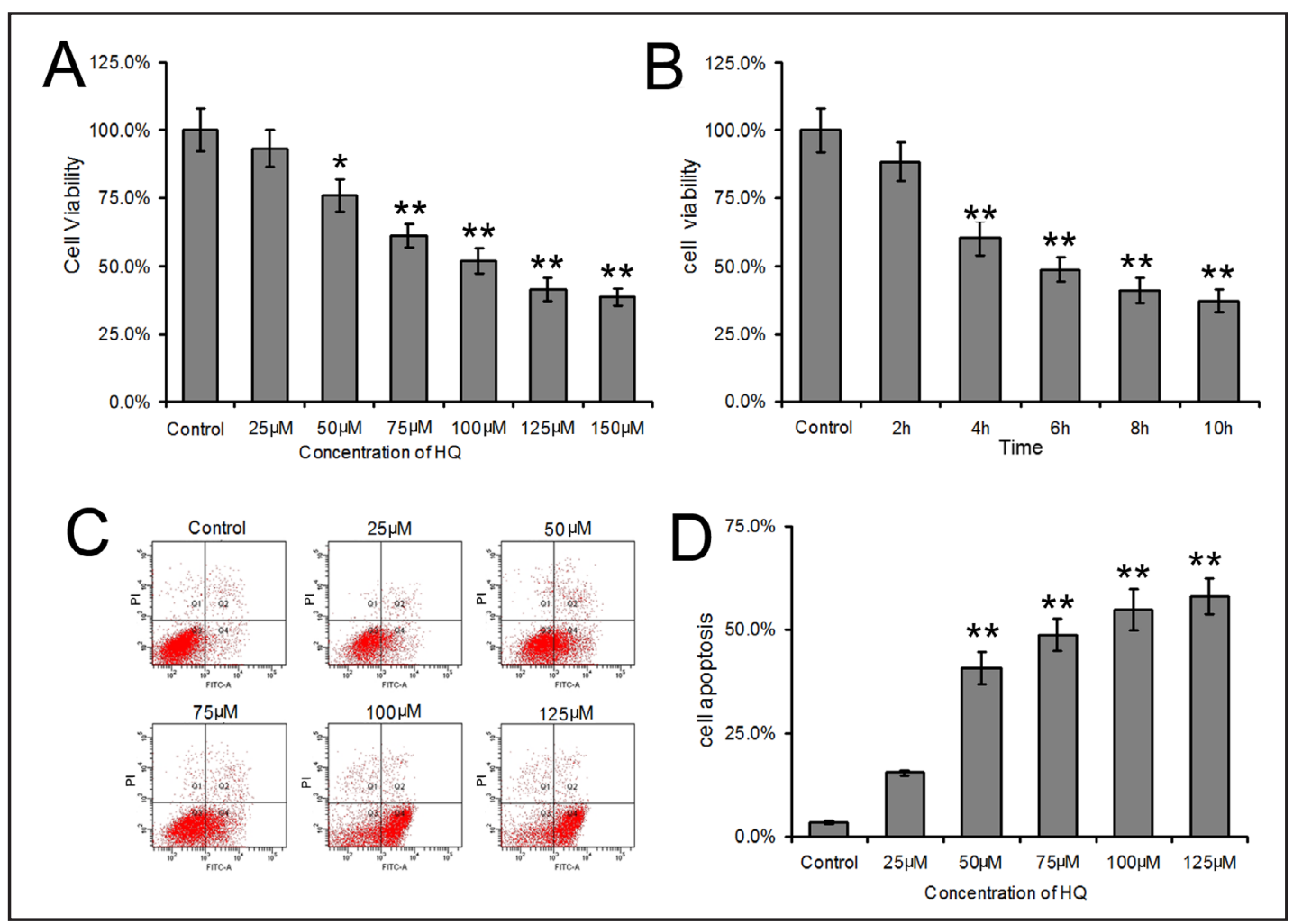

Fig. 1. Cytotoxicity of HQ in BMSCs. (A) BMSCs were exposed to HQ (25, 50, 75, 100, 125, and $150 \mu \mathrm{M})$ for $24 \mathrm{~h}$ or (B) $125 \mu \mathrm{M}$ HQ for 2, 4, 6, 8, and $10 \mathrm{~h}$ and cell viability was assessed using the MTT assay. (C and D) BMSCs were exposed to HQ $(25,50,75,100$, and $125 \mu \mathrm{M})$ for $24 \mathrm{~h}$ and apoptosis was determined by Annexin V-FITC/PI flow cytometry. All assays were repeated three times. Results are shown as the mean \pm SD of three independent experiments $\left({ }^{*} \mathrm{P}<0.05,{ }^{* *} \mathrm{p}<0.01\right)$.

Fig. 2. Effect of HQ on the expression of MDR1. (A) qRT-PCR analysis of MDR1 mRNA levels and (B) Western blot analysis of MDR1 protein levels in cells treated with different doses of HQ $(25,50,75,100$, and $125 \mu \mathrm{M})$ for $24 \mathrm{~h}$ (* $\left.\mathrm{P}<0.05,{ }^{* *} \mathrm{p}<0.01\right)$.

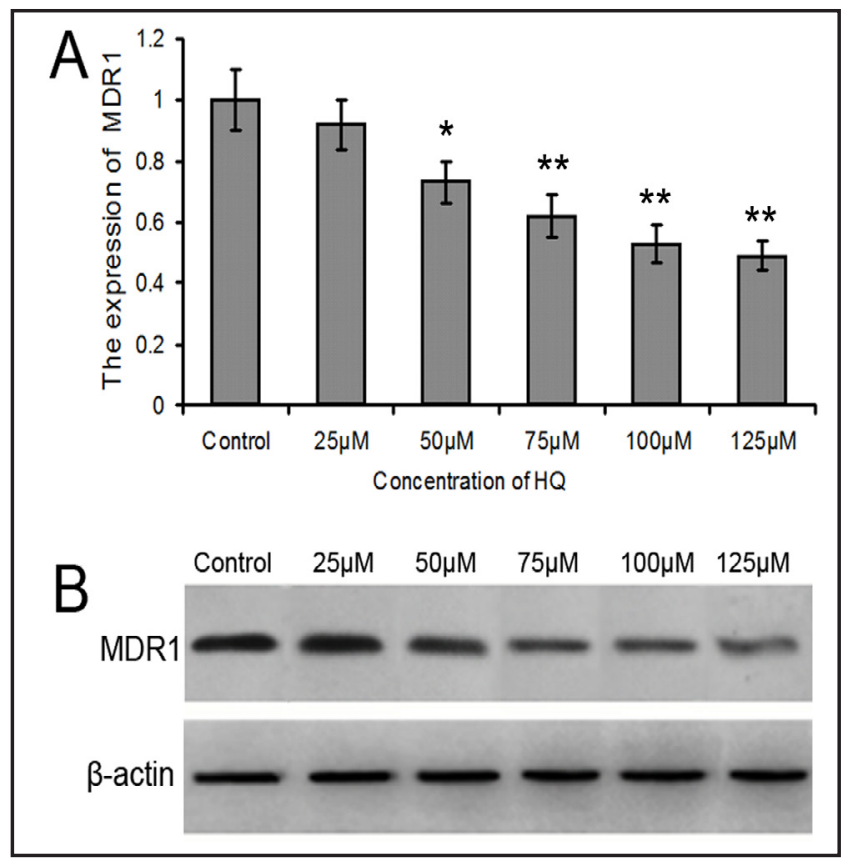

inhibition of the nuclear localization of the p-p65 subunit, as observed in merged images with the nuclear stain DAPI (Fig. 4C). Taken together, these results suggested that HQ inhibits the activation of NF- $\kappa B$ in BMSCs. 
Fig. 3. Effect of MDR1 overexpression or knockdown on BMSC viability in response to HQ. (A and B) BMSCs were transfected with vectors overexpressing(OE) or silencing MDR1(KO) and cell viability (A) and apoptosis (B) were assessed in response to treatment with different doses of HQ (25 $125 \mu \mathrm{M})$ for $24 \mathrm{~h}\left({ }^{*} \mathrm{P}<0.05\right)$.
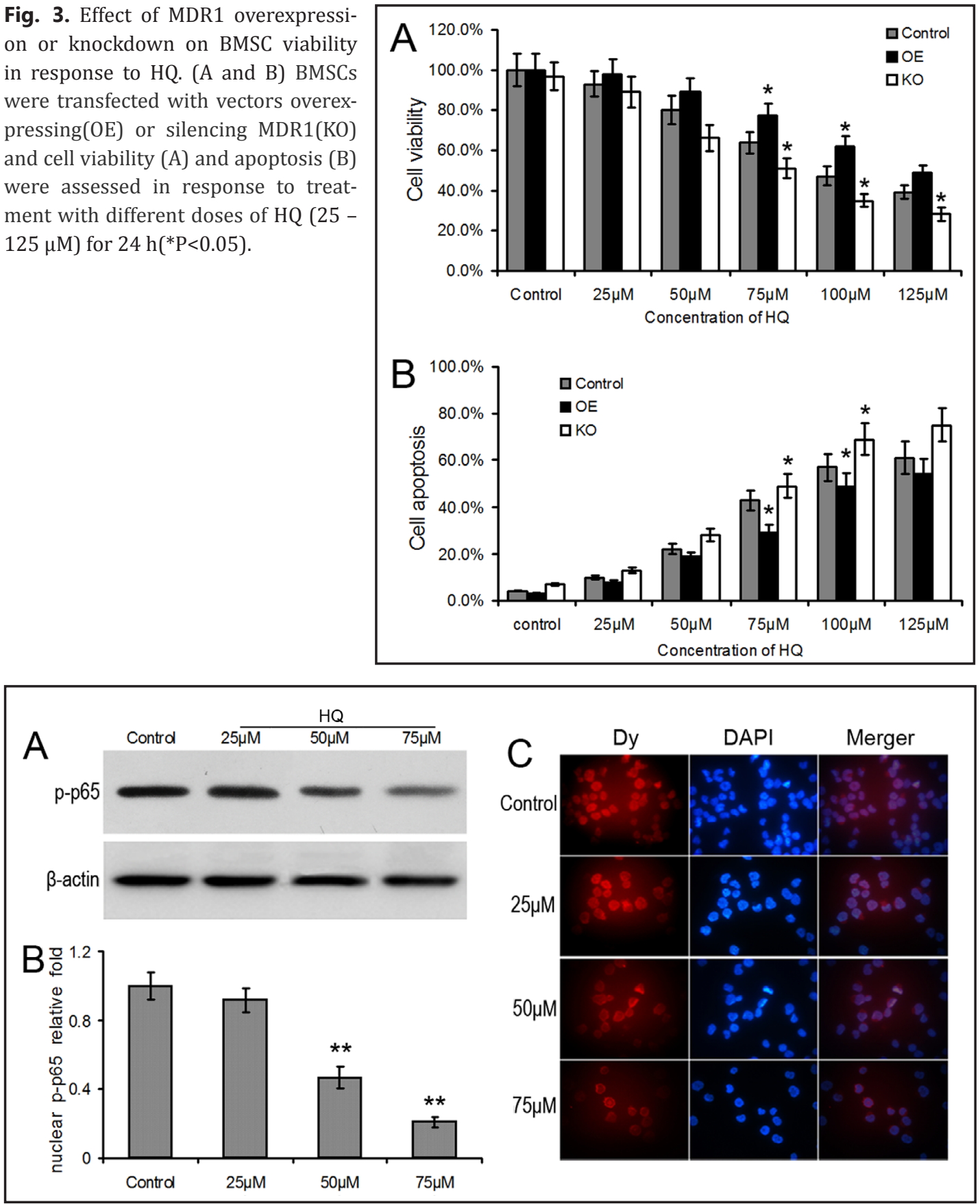

Fig. 4. Effect of HQ on NF- $\mathrm{HB}$ activation in BMSCs. (A) The expression of p65 was assessed by Western blotting in nuclear extracts of BMSCs treated with different concentrations of $H Q\left({ }^{*} \mathrm{P}<0.05,{ }^{* *} \mathrm{p}<0.01\right)$. (B) Results of densitometric scan of the blot shown in (A). (C) Immunofluorescence detection of NF- $\kappa$ B p65 (DyLight 649, Dy) and nuclear staining with DAPI and merged images (original magnification $\times 400$ ).

Inhibition of the NF- $\kappa B$ transduction pathway reduces induced MDR1 expression

Incubation of BMSCs with NF- $\kappa$ B inhibitor PDTC blocked the activates NF- $\kappa B$ Signaling Pathway. There was no significant inhibition in cells pretreated with PDTC at10 $\mu$ M. Cells pretreated with PDTC at 25 and $50 \mu \mathrm{M}$ for $1 \mathrm{~h}$ showed complete inhibition of the NF- $\kappa$ B signal pathway as show in Fig 5A. Reduced MDR1 mRNA expression and protein was detected in BMSCs pretreated with inhibitor PDTC using WB and RT-PCR. This trend showed relationship to PDTC pretreatment, as shown in Fig 5A, B.

\section{KARGER}




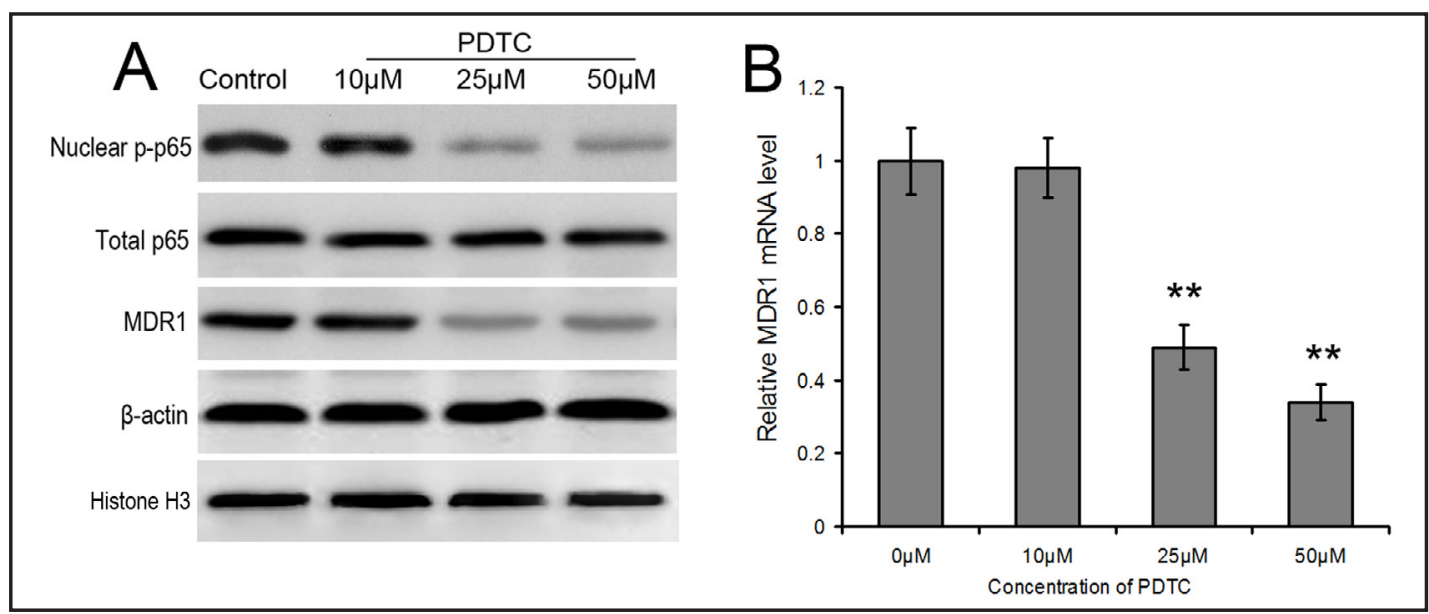

Fig. 5. Inhibit NF- $\kappa B$ downregulate the expression of MDR1. (A) Cells were treat with different doses of an NF- $\kappa B$ inhibitor PDTC and the expression of NF- $\kappa B$ p65 or MDR1 were assessed by Western blotting. The $\beta$-actin (for total p65,MDR1 samples) and Histone H3 (for nuclear-p65 samples) were respectively used as a control for sample loading. (B) BMSCs were treat with different doses of an NF- $\kappa$ B inhibitor PDTC and the mRNA of MDR1 was assessed by qRT-PCR.

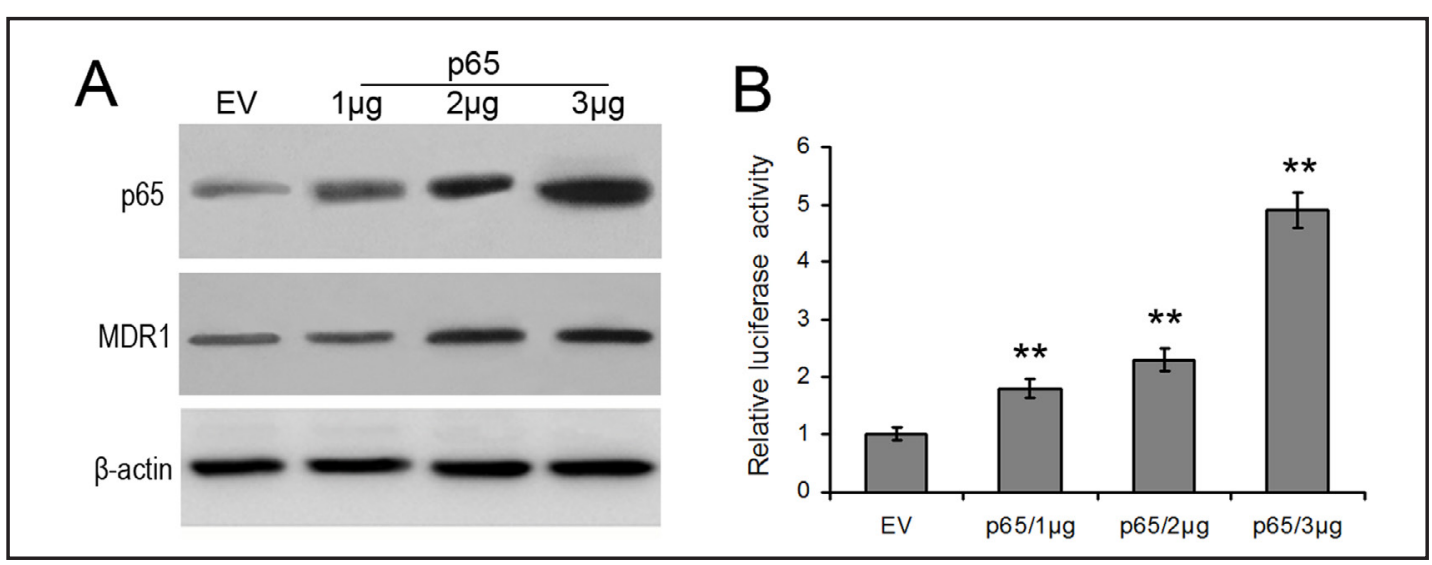

Fig. 6. Effect of NF- $\kappa B$ on the expression of MDR1. (A) Cells were transfected with different doses of an NF$\kappa \mathrm{B}$ p65 expression plasmid and the expression of NF- $\kappa \mathrm{B}$ p65 or MDR1 were assessed by western blotting. (B) BMSCs were transfected with a MDR1 promoter-luciferase reporter plasmid and the effect of NF- $\kappa \mathrm{B}$ p65 was assessed by dual-luciferase reporter assay.

\section{$N F-\kappa B$ regulates MDR1 expression}

Since the expression of MDR1 is known to be regulated by NF- $\kappa B$, we investigated whether the effect of HQ on the expression of MDR1 is mediated by the NF- $\kappa B$ pathway. We therefore examined the effect of ectopic expression of the NF- $\kappa B$ subunit p65 on the levels of MDR1 in BMSCs. Our results showed that p65 dose-dependently upregulated the expression of MDR1 in BMSCs (Fig. 6A). To confirm that the expression of MDR1 is regulated directly by the NF- $\mathrm{BB}$ pathway, we performed a luciferase assay by transfecting cells with a luciferase reporter gene driven by the MDR1 promoter region together with increasing amounts of the p65 protein. The results showed that the $\mathrm{p} 65$ subunit dose-dependently increased luciferase activity, indicating the activation of the MDR1 promoter by NF- $\mathrm{KB}$ (Fig. 6B).

\section{Discussion}

In the present study, we showed that HQ decreased viability and induced apoptosis in BMSCs in a dose and time dependent manner. HQ downregulated MDR1 mRNA and protein 
expression, and MDR1 overexpression attenuated the effect of HQ on cell viability and the induction of apoptosis, whereas MDR1 knockdown enhanced the effect of HQ at specific concentrations. We found that HQ regulates MDR1 expression by modulating the activity of the NF- $\kappa B$ pathway. Taken together, our results suggest that benzene cytotoxicity is mediated by the downregulation of MDR1 via the modulation of the NF- $\kappa B$ pathway.

Benzene toxicity has been demonstrated even in response to low levels of occupational exposure, affecting white blood cell and platelet counts as well as significantly affecting the colony forming ability of myeloid stem and progenitor cells [27]. Despite the known association between benzene exposure and the development of leukemia, the exact mechanism remains elusive and other environmental or genetic factors contributing to leukemia etiology need to be identified. The inhibition of MDR1 has been suggested as a potential mechanism causing the accumulation of benzene intermediate compounds in the bone marrow, and thus an underlying cause of the hematotoxicity of benzene[28]. MDR1 was identified three decades ago as a drug export pump whose expression was induced in response to chemical drug application, leading to multidrug resistance. Since then, MDR1 has been studied extensively because of the role of its encoded protein P-gp in extruding drugs from cancer cells, thereby conferring resistance to chemotherapeutic agents. P-gp expression is a marker of chemoresistance in leukemias, lymphomas, and osteosarcomas among several malignancies [29-31]. We showed that MDR1 overexpression attenuated the effect of HQ on decreasing BMSC viability and inducing apoptosis, and HQ downregulated MDR1 expression in BMSCs, indicating that the cytotoxicity of HQ may be mediated by the downregulation of MDR1.

Numerous signals are involved in the regulation of MDR1, among them the transcription factor NF- $\kappa B$ [28]. A binding site for NF- $\kappa B$ was identified in the MDR1 promoter and shown to play a role in its transcriptional activation $[32,33]$. NF- $\kappa B$ plays an antiapoptotic role in

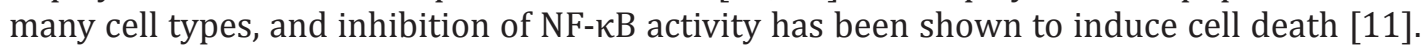
However, NF- $\kappa B$ can also play a proapoptotic role in response to chemotherapeutic drugs, and induction of p53 induces apoptosis through the activation of NF- $\kappa \mathrm{B}[34,35]$. Inhibition of NF- $\kappa B$ was shown to increase the cellular response to cytotoxic agents in different tumors [36-38]. Activation of NF- $\kappa B$ upregulates the expression of MDR1 in human hepatoma cells [39], and binding of NF- $\mathrm{BB}$ to the MDR1 promoter induces drug resistance by upregulating the expression of P-gp in colon cancer cells [11]. Clitocine, a natural compound, was recently shown to suppress P-gp associated multidrug resistance by downregulating NF- $\kappa$ B in human hepatoma cells [40]. These studies support the role of NF- $\kappa B$ in the modulation of MDR1 expression and drug resistance and thus the results of the present study. Here, we showed that HQ inhibited NF- $\kappa$ B activity and ectopic expression of the NF- $\kappa$ B $\mathrm{p} 65$ subunit upregulated MDR1, suggesting that the cytotoxic effect of HQ is mediated by the downregulation of MDR1

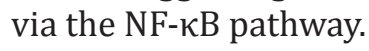

In the present study, we examined potential signaling pathways mediating the effect of benzene and its metabolites on the viability of BMSCs. However, the cytotoxic effect of HQ could be mediated by different pathways, and the relationship between TNF- $\alpha$, MDR1 and NF- $\kappa$ B could involve crosstalk between these and other as yet unidentified pathways triggered by stimulation by a toxic compound. Further study is necessary to elucidate the mechanisms underlying the cytotoxic effect of benzene and the interplay between the molecules involved. In addition, other mechanisms potentially mediating the effect of HQ on BMSCs should be investigated, such as the involvement of caspases, as the induction of cell death by benzene and its metabolites has been shown to be mediated by the modulation of several genes including Bcl-2, Bax, caspases 9, 11 and 12, ELK-member of ETS oncogene family and Fau [41, 42], as well as by oxidative DNA damage resulting from the production of reactive oxygen species in response to HQ [43].

In conclusion, we showed that the benzene metabolite HQ decreases cell viability and induces apoptosis in BMSCs by downregulating the expression of MDR1 via a mechanism involving the NF- $\mathrm{KB}$ pathway. 


\section{Acknowledgments}

Grant support from the Nature Science Foundation (81202160),Shanghai Municipal Health Bureau youth Foundation (2012-138, 2012-167), Shanghai Municipal Health Bureau Key Project (2011-19), Shanghai YoungPhysicianTraining Program (2012-30, 2012-31).

\section{Disclosure Statement}

The authors have no conflict of interest.

\section{References}

1 Minciullo PL, Navarra M, Calapai G, Gangemi S: Cytokine network involvement in subjects exposed to benzene. J Immunol Res 2014;2014:937987.

2 Wilbur S, Wohlers D, Paikoff S, Keith LS, Faroon O: Atsdr evaluation of potential for human exposure to benzene. Toxicol Ind Health 2008;24:399-442.

3 Arnold SM, Angerer J, Boogaard PJ, Hughes MF, O'Lone RB, Robison SH, Schnatter AR: The use of biomonitoring data in exposure and human health risk assessment: Benzene case study. Crit Rev Toxicol 2013;43:119-153.

$4 \quad$ Snyder R, Witz G, Goldstein BD: The toxicology of benzene. Environ Health Perspect 1993;100:293-306.

5 Baan R, Grosse Y, Straif K, Secretan B, El Ghissassi F, Bouvard V, Benbrahim-Tallaa L, Guha N, Freeman C, Galichet L, Cogliano V, Wo WIARCM: Special report: Policy a review of human carcinogens-part f: Chemical agents and related occupations. Lancet Oncology 2009;10:1143-1144.

6 McHale CM, Zhang LP, Smith MT: Current understanding of the mechanism of benzene-induced leukemia in humans: Implications for risk assessment. Carcinogenesis 2012;33:240-252.

7 Schnatter AR, Glass DC, Tang G, Irons RD, Rushton L: Myelodysplastic syndrome and benzene exposure among petroleum workers: An international pooled analysis. J Natl Cancer Inst 2012;104:1724-1737.

8 Gaskell M, McLuckie KI, Farmer PB: Genotoxicity of the benzene metabolites para-benzoquinone and hydroquinone. Chem Biol Interact 2005;153-154:267-270.

9 North M, Tandon VJ, Thomas R, Loguinov A, Gerlovina I, Hubbard AE, Zhang L, Smith MT, Vulpe CD: Genome-wide functional profiling reveals genes required for tolerance to benzene metabolites in yeast. PLoS One 2011;6:e24205.

10 Smith MT: The mechanism of benzene-induced leukemia: A hypothesis and speculations on the causes of leukemia. Environ Health Perspect 1996;104:1219-1225.

11 Bentires-Alj M, Barbu V, Fillet M, Chariot A, Relic B, Jacobs N, Gielen J, Merville MP, Bours V: Nf-kappa $\mathrm{b}$ transcription factor induces drug resistance through mdr1 expression in cancer cells. Oncogene 2003;22:90-97.

12 Chin KV, Ueda K, Pastan I, Gottesman MM: Modulation of activity of the promoter of the human mdr1 gene by ras and p53. Science 1992;255:459-462.

13 Cornwell MM, Smith DE: Sp1 activates the mdr1 promoter through one of two distinct g-rich regions that modulate promoter activity. J Biol Chem 1993;268:19505-19511.

14 Zhou G, Kuo MT: Wild-type p53-mediated induction of rat mdr1b expression by the anticancer drug daunorubicin. J Biol Chem 1998;273:15387-15394.

15 Zhou G, Kuo MT: Nf-kappab-mediated induction of mdr1b expression by insulin in rat hepatoma cells. J Biol Chem 1997;272:15174-15183.

16 Fine RL, Chambers TC, Sachs CW: P-glycoprotein, multidrug resistance and protein kinase c. Stem Cells 1996;14:47-55.

17 Tang XY, Zhu YQ: Epigallocatechin-3-gallate suppressed the over-expression of hsp 70 and mdr1 induced by heat shock in sgc 7901. J Chemother 2008;20:355-360. 
18 Fujita T, Ito K, Izumi H, Kimura M, Sano M, Nakagomi H, Maeno K, Hama Y, Shingu K, Tsuchiya S, Kohno K, Fujimori M: Increased nuclear localization of transcription factor $\mathrm{y}$-box binding protein 1 accompanied by up-regulation of p-glycoprotein in breast cancer pretreated with paclitaxel. Clin Cancer Res 2005;11:88378844.

19 David GL, Yegnasubramanian S, Kumar A, Marchi VL, De Marzo AM, Lin X, Nelson WG: Mdr1 promoter hypermethylation in mcf-7 human breast cancer cells: Changes in chromatin structure induced by treatment with 5-aza-cytidine. Cancer Biol Ther 2004;3:540-548.

20 Kim SN, Kim NH, Lee W, Seo DW, Kim YK: Histone deacetylase inhibitor induction of p-glycoprotein transcription requires both histone deacetylase 1 dissociation and recruitment of caat/enhancer binding protein beta and pcaf to the promoter region. Mol Cancer Res 2009;7:735-744.

21 Shi C: Recent progress toward understanding the physiological function of bone marrow mesenchymal stem cells. Immunology 2012;136:133-138.

22 Diederichs S, Zachert K, Raiss P, Richter W: Regulating chondrogenesis of human mesenchymal stromal cells with a retinoic acid receptor-beta inhibitor: Differential sensitivity of chondral versus osteochondral development. Cell Physiol Biochem 2014;33:1607-1619.

23 Haynesworth SE, Baber MA, Caplan AI: Cytokine expression by human marrow-derived mesenchymal progenitor cells in vitro: Effects of dexamethasone and il-1 alpha. J Cell Physiol 1996;166:585-592.

24 Caplan AI, Bruder SP: Mesenchymal stem cells: Building blocks for molecular medicine in the 21st century. Trends Mol Med 2001;7:259-264.

25 Kordes C, Sawitza I, Gotze S, Haussinger D: Hepatic stellate cells support hematopoiesis and are liverresident mesenchymal stem cells. Cell Physiol Biochem 2013;31:290-304.

26 Lee YS, Lee JE, Park HY, Lim YS, Lee JC, Wang SG, Lee BJ: Isolation of mesenchymal stromal cells (mscs) from human adenoid tissue. Cell Physiol Biochem 2013;31:513-524.

27 Smith MT, Zhang L, McHale CM, Skibola CF, Rappaport SM: Benzene, the exposome and future investigations of leukemia etiology. Chem Biol Interact 2011;192:155-159.

28 Huang JS, Zhao MD, Shi JM, Zhang JH, Li B, Fan W, Zhou YL: Expression of multidrug resistance 1 and multidrug resistance-related protein 1 in c57bl/ 6 mice treated with benzene. Genet Mol Res 2013;12:5842-5850.

29 Fojo AT, Ueda K, Slamon DJ, Poplack DG, Gottesman MM, Pastan I: Expression of a multidrug-resistance gene in human tumors and tissues. Proc Natl Acad Sci U S A 1987;84:265-269.

30 Marie JP, Zittoun R, Sikic BI: Multidrug resistance (mdr1) gene expression in adult acute leukemias: Correlations with treatment outcome and in vitro drug sensitivity. Blood 1991;78:586-592.

31 Yuen AR, Sikic BI: Multidrug resistance in lymphomas. J Clin Oncol 1994;12:2453-2459.

32 Ogretmen B, Safa AR: Negative regulation of mdr1 promoter activity in mcf-7, but not in multidrug resistant mcf-7/adr, cells by cross-coupled nf-kappa b/p65 and c-fos transcription factors and their interaction with the caat region. Biochemistry 1999;38:2189-2199.

33 Wang Y, Liu X, Zhang HT, Yu M, Wang H: [nf-kappab regulating expression of mdr1 gene and p-gp to reverse drug-resistance in leukemic cells]. Zhongguo Shi Yan Xue Ye Xue Za Zhi 2007;15:950-954.

34 Barkett M, Gilmore TD: Control of apoptosis by rel/nf-kappab transcription factors. Oncogene 1999;18:6910-6924.

35 Ryan KM, Ernst MK, Rice NR, Vousden KH: Role of nf-kappab in p53-mediated programmed cell death. Nature 2000;404:892-897.

36 Aydin C, Sanlioglu AD, Bisgin A, Yoldas B, Dertsiz L, Karacay B, Griffith TS, Sanlioglu S: Nf-kappab targeting by way of ikk inhibition sensitizes lung cancer cells to adenovirus delivery of trail. BMC Cancer 2010;10:584.

37 Wang CY, Cusack JC, Jr., Liu R, Baldwin AS, Jr.: Control of inducible chemoresistance: Enhanced anti-tumor therapy through increased apoptosis by inhibition of nf-kappab. Nat Med 1999;5:412-417.

38 Bauer JA, Lupica JA, Schmidt H, Morrison BH, Haney RM, Masci RK, Lee RM, Didonato JA, Lindner DJ: Nitrosylcobalamin potentiates the anti-neoplastic effects of chemotherapeutic agents via suppression of survival signaling. PLoS One 2007;2:e1313.

39 Kuo MT, Liu Z, Wei Y, Lin-Lee YC, Tatebe S, Mills GB, Unate H: Induction of human mdr1 gene expression by 2 -acetylaminofluorene is mediated by effectors of the phosphoinositide 3-kinase pathway that activate nf-kappab signaling. Oncogene 2002;21:1945-1954. 


\section{Cellular Physiology Cell Physiol Biochem 2015;37:592-602}

\begin{tabular}{|l|l|}
\hline DOI: 10.1159/000430379 & ( 2015 S. Karger AG, Basel
\end{tabular}

Huang et. al.: The Cytotoxic Effect of Hydroquinone is Mediated by MDR1

40 Sun J, Yeung CA, Co NN, Tsang TY, Yau E, Luo K, Wu P, Wa JC, Fung KP, Kwok TT, Liu F: Clitocine reversal of p-glycoprotein associated multi-drug resistance through down-regulation of transcription factor nf-kappab in r-hepg2 cell line. PLoS One 2012;7:e40720.

41 Inayat-Hussain SH, Ibrahim HA, Siew EL, Rajab NF, Chan KM, Williams GT, Ross D: Modulation of the benzene metabolite hydroquinone induced toxicity: Evidence for an important role of fau. Chem Biol Interact 2010;184:310-312.

42 Yoon BI, Li GX, Kitada K, Kawasaki Y, Igarashi K, Kodama Y, Inoue T, Kobayashi K, Kanno J, Kim DY, Inoue T, Hirabayashi Y: Mechanisms of benzene-induced hematotoxicity and leukemogenicity: Cdna microarray analyses using mouse bone marrow tissue. Environ Health Perspect 2003;111:1411-1420.

43 Inayat-Hussain SH, Ross D: Intrinsic pathway of hydroquinone induced apoptosis occurs via both caspasedependent and caspase-independent mechanisms. Chem Res Toxicol 2005;18:420-427. 